Published in final edited form as:

J Aging Health. 2017 February ; 29(1): 172-184. doi:10.1177/0898264316634571.

\title{
Association of Hearing Impairment and Anxiety in Older Adults
}

Kevin J. Contrera, MPH ${ }^{1}$, Josh Betz, MS ${ }^{1}$, Jennifer Deal, $\mathrm{PhD}^{1}$, Janet S. Choi, MPH ${ }^{1}$, Hilsa N. Ayonayon, $\mathrm{PhD}^{2}$, Tamara Harris, $\mathrm{PhD}^{3}$, Elizabeth Helzner, $\mathrm{PhD}^{4}$, Kathryn R. Martin, PhD MPH $^{5}$, Kala Mehta, DSc ${ }^{6}$, Sheila Pratt, PhD $^{1,6}$, Susan M. Rubin, MPH $^{2}$, Suzanne Satterfield, MD DPH ${ }^{7}$, Kristine Yaffe, MD $^{2}$, Eleanor M. Simonsick, $\mathrm{PhD}^{8}$, Frank R. Lin, MD, $\mathrm{PhD}^{1}$, and for the Health ABC Study

1'Johns Hopkins University, Baltimore, MD, USA

${ }^{2}$ University of California, San Francisco, USA

${ }^{3}$ National Institute on Aging, Baltimore, MD, USA

${ }^{4}$ State University of New York Downstate Medical Center, Brooklyn, New York City, USA

${ }^{5}$ Institute of Applied Health Sciences School of Medicine and Dentistry, Aberdeen, UK

${ }^{6}$ VA Pittsburgh Healthcare System, PA, USA

${ }^{7}$ University of Tennessee Health Science Center, Memphis, USA

${ }^{8}$ National Institute on Aging, Baltimore, MD, USA

\section{Abstract}

Objective-The objective of the study is was investigate the association between hearing impairment and anxiety.

Method-We conducted a cross-sectional analysis of 1,732 community-based adults aged 76 to 85 years who participated in the Health Aging and Body Composition (ABC) study. Logistic regression models were adjusted for demographic and cardiovascular risk factors. Hearing impairment was defined by the speech-frequency pure tone average. Anxiety was defined as reporting two symptoms of at least "a little" or one symptom "quite a bit" on the three-item Hopkins Symptom Checklist.

Results-Compared with individuals with no hearing impairment, the odds of prevalent anxiety were higher among individuals with mild hearing impairment (odds ratio $[\mathrm{OR}]=1.32,95 \%$ confidence interval $[\mathrm{CI}]=[1.01,1.73])$ and moderate or greater hearing impairment $(\mathrm{OR}=1.59$,

Reprints and permissions: sagepub.com/journalsPermissions.nav

Corresponding Author: Frank R. Lin, Johns Hopkins Center on Aging \& Health, Johns Hopkins University, 2024 E. Monument St, Suite 2-700, Baltimore, MD 21205, USA. flin1@jhmi.edu.

Authors' Note

The contents of the article are solely the responsibility of the authors.

Declaration of Conflicting Interests

The authors declared the following potential conflicts of interest with respect to the research, authorship, and/or publication of this article: Dr. Frank Lin reports being a consultant to Cochlear, on the scientific advisory board for Autifony and Pfizer, and a speaker for Med El and Amplifon. 
$95 \% \mathrm{CI}=[1.14,2.22])$. Hearing aid use was not significantly associated with lower odds of anxiety.

Discussion-Hearing impairment is independently associated with greater odds of anxiety symptoms in older adults.

\section{Keywords}

hearing; anxiety; mental health; geriatrics

\section{Introduction}

Hearing deficits are common in older adults; however, the prevalence of hearing loss doubles with every age decade, such that by the age of 70, two-thirds of adults are hearing impaired (Lin, Niparko, \& Ferrucci, 2011; Lin, Thorpe, Gordon-Salant, \& Ferrucci, 2011). Individuals with hearing loss have been shown to have poorer health outcomes, including decreased cognitive function (Lin, Ferrucci, et al., 2011; Lin et al., 2013; Valentijn et al., 2005), quality of life (Ciorba, Bianchini, Pelucchi, \& Pastore, 2012; Wallhagen, Strawbridge, Shema, Kurata, \& Kaplan, 2001), and mobility (Chen, Genther, Betz, \& Lin, 2014).

Mental health is a key component of healthy aging. The estimated prevalence of anxiety disorders ranges from $9.2 \%$ to $28.7 \%$ with the highest rates in older adults (Somers, Goldner, Waraich, \& Hsu, 2006). Limited research has examined how hearing loss may affect anxiety (Chung, Hung, Lin, \& Sheu, 2015; Fellinger, Holzinger, Gerich, \& Goldberg, 2007; Nachtegaal et al., 2009; Tambs, 2004). Hearing impairment (HI) could plausibly contribute to anxiety and poor mental health outcomes through mediating pathways of cognitive impairment (Lin, Ferrucci, et al., 2011; Lin et al., 2013; Valentijn et al., 2005), social isolation (Mick, Kawachi, \& Lin, 2014), or disability (Chen et al., 2014). Sensory deprivation has also been proposed as a possible cause for anxiety and mood disturbances (Gilmartin, Grota, \& Sousa, 2013; Heine \& Browning, 2002). Alternatively, shared common etiologic factors such as age, cardiovascular disease (Gates, Cobb, Dagostino, \& Wolf, 1993), or other demographic factors (Agrawal, Platz, \& Niparko, 2008) could underlie any observed association between $\mathrm{HI}$ and anxiety.

In this study, we investigated whether HI, objectively measured with audiometry, was associated with anxiety symptoms in a population of U.S. community-dwelling older adults followed in the Health, Aging and Body Composition (Health ABC) study. Self-reported measures, derived from a validated screening tool (Bech, Bille, Moller, Hellstrom, \& Ostergaard, 2014) were used to assess anxiety. We hypothesized that greater HI is associated with greater anxiety symptoms, independent of demographic and cardiovascular risk factors.

\section{Method}

\section{Study Design and Population}

We conducted a cross-sectional analysis of data from the Health ABC study, a prospective observational study that enrolled 3,075 well-functioning, community-dwelling older adults 
aged 70 to 79 from 1997 to 1998 (aged 76-85 years at Study Year 6; Simonsick et al., 2001). Study participants were recruited from a random sample of White and Black Medicare beneficiaries living in Pittsburgh, Pennsylvania and Memphis, Tennessee. Only White and Black individuals were recruited because one of the original study objectives was to examine race-related differences in body composition parameters, and resources were insufficient to include other races. To be eligible, participants had to report no difficulty walking a quarter of a mile, climbing 10 steps without resting, or performing basic activities of daily living. Our analytic cohort was composed of individuals who completed audiometric testing administered in Year 5 and anxiety assessments measured in Year $6(n=1,732)$. Participants were excluded from our analysis for various causes (evidence of cognitive impairment indicated by Modified Mini-Mental State examination [3MS] score < 80 at study enrollment [ $n=149$; Teng \& Chui, 1987], inability to complete hearing testing [ $n=500]$, death prior to Year 6 [ $n=378]$, withdrawal from study prior to Year $6[n=12]$, missed anxiety measures in Year 6 [ $n=273]$, or missing covariates $[n=31])$. Compared with the individuals excluded from our analytic cohort, study participants were more likely to be younger, White, higher educated, and former smokers. All participants provided written informed consent, and the institutional review boards of both sites approved this study.

\section{Audiometry}

Air conduction thresholds were obtained in each ear from 0.25 to $8 \mathrm{kHz}$ with supra-aural headphones (TDH 39; Telephonics Corporation) using an audiometer (MA40; Maico Diagnostics) in a sound-proof booth and calibrated to American National Standards Institute standards (ANSI/ASA S3.6-1996). We calculated a speech-frequency pure tone average (PTA) using audiometric thresholds at $0.5,1,2$, and $4 \mathrm{kHz}$ in the better-hearing ear in accordance with the World Health Organization-established cutoffs for clinically significant hearing loss (i.e., none < $25 \mathrm{~dB} \mathrm{HL}$, mild 25-40 dB HL, moderate or greater > $40 \mathrm{~dB} \mathrm{HL}$; World Health Organization, 2014).

\section{Anxiety}

Anxiety symptom measurements were derived from the validated Hopkins Symptom Checklist (Parloff, Kelman, \& Frank, 1954). Three questions addressing anxiety were used: "During the past week: (a) have you felt fearful; (b) have you felt nervous/shaky inside; and (c) have you felt tense/keyed up?" These questions were answered on a 4-level ordinal scale: no, a little, quite a bit, or a lot. Previous research has demonstrated the utility of the abbreviated Hopkins Symptom Checklist, varying between three to four questions, as a screening tool for anxiety symptoms (Brenes, Guralnik, Williamson, Fried, \& Penninx, 2005; Mehta et al., 2007; Tambs 2004). Based on previous studies (Kasper \& Simonsick 1995; Mehta et al., 2003; Simonsick, Guralnik, \& Fried, 1999), we defined individuals as having anxiety symptoms if they rated any two symptoms as at least "a little" or any one symptom as at least "quite a bit."

\section{Covariates}

At enrollment (Year 1), participants reported their age, sex, race, and educational history. Participants were also identified at enrollment as having hypertension or diabetes if they reported ever being told so by a physician, if diagnosed during the clinical visit, or if they 
recorded taking medications for either condition (Lin et al., 2013). Stroke history was assessed by the question, "Has the doctor ever told you that you had a stroke, CVA, cerebrovascular accident, TIA, transient ischemic attack or mini-stroke?" Smoking status, defined as current, former, or never, was based on an interviewer-administered questionnaire. These cardiovascular risk factors and demographic characteristics are known to be associated with HI (Linssen, van Boxtel, Joore, \& Anteunis, 2014) and were included as covariates in our analytic model to adjust for potential confounding. At Year 5, participants' hearing aid use was assessed by the interviewer-administered question, "Do you wear a hearing aid?" with potential answers, "yes, no, or don't know." Depressive symptomatology was measured in Year 6 and defined as a score $>15$ on the validated 20item Center for Epidemiologic Studies Depression Scale (CES-D; Radloff, 1977).

\section{Statistical Analysis}

Baseline characteristics of participants were compared using the Kruskal-Wallis test and Fisher's exact test where appropriate. The relationship between HI and anxiety was analyzed using logistic regression. Models were sequentially adjusted for demographic characteristics (age, sex, race, and education) and cardiovascular risk factors (smoking status, hypertension, diabetes, and stroke). As a sensitivity analysis, depression (CES-D) was added as a covariate to our final model. This is because previous studies have suggested an association between HI and depression (Li et al., 2014; Mener, Betz, Genther, Chen, \& Lin, 2013), and anxiety and depression can overlap in their clinical presentation; hence, it is unclear whether depression is truly a confounder of the association between HI and anxiety. Effect modification was evaluated through stratification by sex, as women are $70 \%$ more likely than men to experience an anxiety disorder and may be more susceptible to the effects of HI on anxiety (McLean, Asnaani, Litz, \& Hofmann, 2011). As a secondary analysis, hearing threshold was treated as a continuous variable. A threshold of two-tailed $p$ value $<.05$ was considered statistically significant. All analyses were conducted in Stata SE 12 (StataCorp, College Station, Texas).

\section{Results}

Our analytic cohort comprised 1,732 adults characterized in Table 1. Participants with mild HI $(n=649)$ and moderate or greater HI $(n=352)$ were more likely to be older, male, White, less educated, enrolled at the Memphis site, and have a history of smoking than participants with no HI $(n=731)$. There was no difference in history of hypertension, diabetes, or stroke between individuals with and without HI.

The association between $\mathrm{HI}$ and anxiety was investigated through logistic regression models adjusted for demographic (age, sex, race, and education) and cardiovascular risk factors (history of stroke, smoking, diabetes, and hypertension; Table 2). In the fully adjusted model, we observed that the odds of anxiety were higher among individuals with mild $\mathrm{HI}$ $(\mathrm{OR}=1.32,95 \% \mathrm{CI}=[1.01,1.73])$ and with moderate or greater $\mathrm{HI}(\mathrm{OR}=1.59,95 \% \mathrm{CI}=$ $[1.14,2.22])$ compared with individuals with no HI. Secondary analysis of hearing threshold as a continuous variable yielded similar results - each $10 \mathrm{~dB}$ increase in PTA was associated with a $12 \%$ higher odds of prevalent anxiety $(\mathrm{OR}=1.12,95 \% \mathrm{CI}=[1.02,1.23])$. Additional 
analyses stratified by sex yielded similar results in men and women (women: mild HI OR = $1.26,95 \% \mathrm{CI}=[0.91,1.75]$, moderate or greater $\mathrm{HI} \mathrm{OR}=1.68,95 \% \mathrm{CI}=[1.07,2.62]$; men: mild HI OR $=1.51,95 \% \mathrm{CI}=[0.92,2.51]$, moderate or greater $\mathrm{HI} \mathrm{OR}=1.65,95 \% \mathrm{CI}=$ [0.96, 2.84], compared with no HI). Our results were not substantially attenuated by adjustment for depression (mild $\mathrm{HI} \mathrm{OR}=1.28,95 \% \mathrm{CI}=[0.96,1.70]$; moderate or greater $\mathrm{HI} \mathrm{OR}=1.6,95 \% \mathrm{CI}=[1.12,2.27])$.

To explore whether hearing aid use was associated with lower anxiety, we included hearing aid use as a variable in a model restricted to individuals with $\mathrm{HI}(n=1,001,22.4 \%$ reporting hearing aid use [Table 1]). Among individuals with mild HI $(n=649)$ and moderate or greater HI $(n=352)$, hearing aid use was not significantly associated with a lower odds of anxiety (mild $\mathrm{HI} \mathrm{OR}=0.86,95 \% \mathrm{CI}=[0.48,1.56]$; moderate or greater $\mathrm{HI} \mathrm{OR}=0.85,95 \%$ $\mathrm{CI}=[0.50,1.43] ;$ all $\mathrm{HI} \mathrm{OR}=0.93,95 \% \mathrm{CI}=[0.66,1.31])$.

\section{Conclusion}

Our results demonstrate that $\mathrm{HI}$ is independently associated with anxiety in communitydwelling older adults with individuals with mild HI having $32 \%$ higher odds of anxiety, and individuals with moderate or greater $\mathrm{HI}$ having $59 \%$ higher odds of anxiety compared with individuals with no HI. Our results were robust to adjustment for multiple potential confounders.

Although several studies have explored an association between $\mathrm{HI}$ and depression ( $\mathrm{Li}$ et al., 2014; Mener et al., 2013), few have examined other mental health outcomes. In a large survey of Norwegian adults aged 20 to 101 years, Tambs (2004) identified a moderate association of HI with anxiety only in adults 20 to 64 years of age, but did not find an association with adults $>65$ years of age. This cross-sectional study also utilized the Hopkins Symptom Checklist but did not identify a significant association of hearing and anxiety in adults aged $>64$ years. This lack of association may be secondary to survey non-response bias (response rate of 69\%), treatment of positively skewed anxiety score as a continuous variable, or differences in cross-cultural factors that may influence the association between $\mathrm{HI}$ and anxiety in older adults.

A Dutch study examining the association of HI, identified by an online speech-in-noise screening test, and anxiety in 1,511 adults 18 to 70 years of age suggested a potential link, but failed to reach the threshold for statistical significance (Nachtegaal et al., 2009). This may be a result of a contrast between hearing loss in younger adults (often congenital) versus older adults (often age-related). A population-based study in Taiwan compared the prevalence of anxiety disorder in 3,522 adults diagnosed with sudden sensorineural hearing loss with 10,566 matched controls (Chung et al., 2015). They found that individuals with sudden sensorineural hearing loss were 1.49 times more likely than controls to have been diagnosed with anxiety disorder. This is consistent with our ORs, although it is likely that both hearing loss and anxiety disorders were under diagnosed in this population. These studies suggest that the etiology of the hearing loss may be important to the impact on anxiety symptoms, with post-lingual hearing loss seeming to have a greater association with anxiety. 
A cross-sectional study from Ireland found that $\mathrm{HI}$ was associated with clinically diagnosed "depressive-anxiety syndrome" in adults aged 75 years or greater (Bernabei et al., 2011). However, this study, as well as several others assessing mental health (Gomaa, Elmagd, Elbadry, \& Kader, 2014; Jones, Victor, \& Vetter, 1984), used subjective self-reported measures of hearing loss, which have low sensitivity for identifying HI (Kamil, Genther, \& Lin, 2014). Audiometrically measured HI is particularly important in studying anxiety because individuals who subjectively report anxiety symptoms may be more likely to report a concern for hearing loss (Tambs, 2004).

Several mechanisms could explain the observed association between HI and anxiety. Microvascular disease has been associated with both hearing loss (Gates et al., 1993) and poorer mental health (Taylor, Aizenstein, \& Alexopoulos, 2013), suggesting its possibility as a confounder. Likewise, demographic factors, such as age, sex, and education, could underlie the association. However, our results were adjusted for multiple demographic characteristics and cardiovascular risk factors (i.e., stroke, smoking, diabetes, and hypertension). Alternatively, the association of $\mathrm{HI}$ with poorer anxiety outcomes could be mediated through other mental health factors, such as social isolation and sensory deprivation. The role of depression in the association between $\mathrm{HI}$ and anxiety is uncertain. Although depression and anxiety are correlated among older adults (Mehta et al., 2003), there is minimal evidence to suggest depression serves as an intermediate or confounder of the relationship. Notably, the addition of depressive symptoms as a covariate in our final model did not mitigate the association between $\mathrm{HI}$ and anxiety.

In the present study, we observed that individuals using hearing aids had $15 \%$ lower odds of anxiety compared with individuals with $\mathrm{HI}$ who did not use a hearing aid, although these results were not statistically significant. Our cohort was likely underpowered to detect a statistically significant association. Furthermore, hearing aid use was reported as a binary variable and did not include key mediators (e.g., hours worn/day, years of use, communication strategies used) that could influence the strength of association (Knudsen, Oberg, Nielsen, Naylor, \& Kramer, 2010). Longitudinal studies with a more precise measurement of hearing aid use would be necessary to determine whether hearing rehabilitation could affect anxiety among older adults with HI.

Our study has limitations. We cannot establish the temporal relationship between hearing loss and anxiety based on our cross-sectional results, and further longitudinal research is warranted. Three items from the validated Hopkins Symptom Checklist were used for anxiety symptomatology versus a clinical diagnosis or a more comprehensive screening questionnaire. Still, this method is comparable with numerous studies analyzing anxiety in older adult populations (Brenes et al., 2005; Kasper \& Simonsick, 1995; Mehta et al., 2003; Mehta et al., 2007; Simonsick et al., 1999). Covariates (Year 1) and audiometry (Year 5) were recorded prior to the anxiety measurement in Year 6, although these factors are unlikely to significantly change over the course of several years. Our analytic cohort made up 56\% of the original study population. The age range of the participants was fairly narrow (76-85 years), potentially limiting the generalizability of this study to all adults. Residual confounding by unmeasured factors (e.g., socioeconomic factors, work status, lifestyle factors, or other comorbidities) is also plausible. 
In conclusion, our results demonstrate that $\mathrm{HI}$, a highly prevalent condition in older adults, is associated with greater anxiety, independent of demographic characteristics and cardiovascular risk factors. As greater attention is focused on the mental health of an aging population, future research is necessary to elucidate the mechanistic pathways between $\mathrm{HI}$ and anxiety, and to determine whether outcomes are improved with hearing rehabilitative therapies.

\section{Acknowledgments}

\section{Funding}

The authors disclosed receipt of the following financial support for the research, authorship, and/or publication of this article: This article was supported in part by the Eleanor Schwartz Charitable Foundation; a Triological Society/ American College of Surgeons Clinician Scientist Award; the Johns Hopkins Institute for Clinical and Translational Research; the National Institutes of Health (NIH; Grant Numbers K23DC011279, TL1 TR001078); the National Institute on Aging (NIA; Grant Number R01-AG028050, and Contract Numbers N01-AG-6-2101, N01-AG-6-2103, and N01-AG-6-2106); National Institute of Nursing Research (Grant Number R01-NR012459); and the NIH Intramural Research Program.

\section{References}

Agrawal Y, Platz EA, Niparko JK. Prevalence of hearing loss and differences by demographic characteristics among US adults: Data from the National Health and Nutrition Examination Survey, 1999-2004. Archives of Internal Medicine. 2008; 168:1522-1530. DOI: 10.1001/archinte. 168.14.1522 [PubMed: 18663164]

Bech P, Bille J, Moller SB, Hellstrom LC, Ostergaard SD. Psychometric validation of the Hopkins Symptom Checklist (SCL-90) subscales for depression, anxiety, and interpersonal sensitivity. Journal of Affective Disorders. 2014; 160:98-103. DOI: 10.1016/j.jad.2013.12.005 [PubMed: 24445132]

Bernabei V, Morini V, Moretti F, Marchiori A, Ferrari B, Dalmonte E, Rita Atti A. Vision and hearing impairments are associated with depressive-anxiety syndrome in Italian elderly. Aging \& Mental Health. 2011; 15:467-474. DOI: 10.1080/13607863.2011.562483 [PubMed: 21500013]

Brenes GA, Guralnik JM, Williamson J, Fried LP, Penninx BW. Correlates of anxiety symptoms in physically disabled older women. American Journal of Geriatric Psychiatry. 2005; 13:15-22. DOI: 10.1176/appi.ajgp.13.1.15 [PubMed: 15653936]

Chen DS, Genther DJ, Betz J, Lin FR. Association between hearing impairment and self-reported difficulty in physical functioning. Journal of the American Geriatrics Society. 2014; 62:850-856. DOI: 10.1111/jgs.12800 [PubMed: 24779559]

Chung SD, Hung SH, Lin HC, Sheu JJ. Association between sudden sensorineural hearing loss and anxiety disorder: A population-based study. European Archives of Oto-Rhino-Laryngology. 2015; 272:2673-2678. DOI: 10.1007/s00405-014-3235-8 [PubMed: 25115314]

Ciorba A, Bianchini C, Pelucchi S, Pastore A. The impact of hearing loss on the quality of life of elderly adults. Clinical Interventions in Aging. 2012; 7:159-163. DOI: 10.2147/CIA.S26059 [PubMed: 22791988]

Fellinger J, Holzinger D, Gerich J, Goldberg D. Mental distress and quality of life in the hard of hearing. Acta Psychiatrica Scandinavica. 2007; 115:243-245. DOI: 10.1111/j. 1600-0447.2006.00976.x [PubMed: 17302625]

Gates GA, Cobb JL, Dagostino RB, Wolf PA. The relation of hearing in the elderly to the presence of cardiovascular-disease and cardiovascular risk-factors. Archives of Otolaryngology. 1993; 119:156161.

Gilmartin HM, Grota PG, Sousa K. Isolation: A concept analysis. Nursing Forum. 2013; 48:54-60. DOI: 10.1111/nuf.12001 [PubMed: 23379396] 
Gomaa MA, Elmagd MH, Elbadry MM, Kader RM. Depression, Anxiety and Stress Scale in patients with tinnitus and hearing loss. European Archives of Oto-Rhino-Laryngology. 2014; 271:21772184. DOI: 10.1007/s00405-013-2715-6 [PubMed: 24071860]

Heine C, Browning CJ. Communication and psychosocial consequences of sensory loss in older adults: Overview and rehabilitation directions. Disability and Rehabilitation. 2002; 24:763-773. DOI: 10.1080/09638280210129162 [PubMed: 12437862]

Jones DA, Victor CR, Vetter NJ. Hearing difficulty and its psychological implications for the elderly. Journal of Epidemiology \& Community Health. 1984; 38:75-78. [PubMed: 6231351]

Kamil RJ, Genther DJ, Lin FR. Factors associated with the accuracy of subjective assessments of hearing impairment. Ear and Hearing. 2014; 36:164-167. DOI: 10.1097/AUD.0000000000000075

Kasper, JD., Simonsick, EM. Mental health and general well-being. In: Guralnik, JM.Fried, LP.Simonsick, EM.Kasper, JD., Lafferty, ME., editors. The women's health and aging study: Health and social characteristics of older women with disability. Bethesda, MD: National Institute on Aging; 1995. Retrieved from http://www.grc.nia.nih.gov/branches/leps/whasbook/tablcont.htm

Knudsen LV, Oberg M, Nielsen C, Naylor G, Kramer SE. Factors influencing help seeking, hearing aid uptake, hearing aid use and satisfaction with hearing aids: A review of the literature. Trends in Amplification. 2010; 14:127-154. DOI: 10.1177/1084713810385712 [PubMed: 21109549]

Li CM, Zhang X, Hoffman HJ, Cotch MF, Themann CL, Wilson MR. Hearing impairment associated with depression in US adults, National Health and Nutrition Examination Survey 2005-2010. JAMA Otolaryngology— Head \& Neck Surgery. 2014; 140:293-302. DOI: 10.1001/jamaoto. 2014.42 [PubMed: 24604103]

Lin FR, Ferrucci L, Metter EJ, An Y, Zonderman AB, Resnick SM. Hearing loss and cognition in the Baltimore Longitudinal Study of Aging. Neuropsychology. 2011; 25:763-770. DOI: 10.1037/ a0024238 [PubMed: 21728425]

Lin FR, Niparko JK, Ferrucci L. Hearing loss prevalence in the United States. Archives of Internal Medicine. 2011; 171:1851-1852. DOI: 10.1001/archinternmed.2011.506 [PubMed: 22083573]

Lin FR, Thorpe R, Gordon-Salant S, Ferrucci L. Hearing loss prevalence and risk factors among older adults in the United States. Journal of Gerontology, Series A: Biological Sciences \& Medical Sciences. 2011; 66:582-590.

Lin FR, Yaffe K, Xia J, Xue QL, Harris TB, Purchase-Helzner E, Simonsick EM. Hearing loss and cognitive decline in older adults. JAMA Internal Medicine. 2013; 173:293-299. DOI: 10.1001/ jamainternmed.2013.1868 [PubMed: 23337978]

Linssen AM, van Boxtel MP, Joore MA, Anteunis LJ. Predictors of hearing acuity: Cross-sectional and longitudinal analysis. Journal of Gerontology, Series A: Biological Sciences \& Medical Sciences. 2014; 69:759-765. DOI: 10.1093/gerona/glt172

McLean CP, Asnaani A, Litz BT, Hofmann SG. Gender differences in anxiety disorders: Prevalence, course of illness, comorbidity and burden of illness. Journal of Psychiatric Research. 2011; 45:1027-1035. DOI: 10.1016/j.jpsychires.2011.03.006 [PubMed: 21439576]

Mehta KM, Simonsick EM, Penninx BW, Schulz R, Rubin SM, Satterfield S, Yaffe K. Prevalence and correlates of anxiety symptoms in well-functioning older adults: Findings from the health aging and body composition study. Journal of the American Geriatrics Society. 2003; 51:499-504. [PubMed: 12657069]

Mehta KM, Yaffe K, Brenes GA, Newman AB, Shorr RI, Simonsick EM, Covinsky KE. Anxiety symptoms and decline in physical function over 5 years in the health, aging and body composition study. Journal of the American Geriatrics Society. 2007; 55:265-270. DOI: 10.1111/j. 1532-5415.2007.01041.x [PubMed: 17302665]

Mener DJ, Betz J, Genther DJ, Chen D, Lin FR. Hearing loss and depression in older adults. Journal of the American Geriatrics Society. 2013; 61:1627-1629. DOI: 10.1111/jgs.12429 [PubMed: 24028365]

Mick P, Kawachi I, Lin FR. The association between hearing loss and social isolation in older adults. Otolaryngology—Head \& Neck Surgery. 2014; 150:378-384. DOI: 10.1177/0194599813518021 [PubMed: 24384545]

Nachtegaal J, Smit JH, Smits C, Bezemer PD, van Beek JH, Festen JM, Kramer SE. The association between hearing status and psychosocial health before the age of 70 years: Results from an 
internet-based national survey on hearing. Ear and Hearing. 2009; 30:302-312. DOI: 10.1097/ AUD.0b013e31819c6e01 [PubMed: 19322094]

Parloff MB, Kelman HC, Frank JD. Comfort, effectiveness, and self-awareness as criteria of improvement in psychotherapy. American Journal of Psychiatry. 1954; 111:343-352. [PubMed: 13197596]

Radloff LS. The CES-D scale a self-report depression scale for research in the general population. Applied Psychological Measurement. 1977; 1:385-401.

Simonsick EM, Guralnik JM, Fried LP. Who walks? Factors associated with walking behavior in disabled older women with and without self-reported walking difficulty. Journal of the American Geriatrics Society. 1999; 47:672-680. [PubMed: 10366165]

Simonsick EM, Newman AB, Nevitt MC, Kritchevsky SB, Ferrucci L, Guralnik JM, Harris T. Measuring higher level physical function in well-functioning older adults: Expanding familiar approaches in the Health ABC study. Journal of Gerontology, Series A: Biological Sciences \& Medical Sciences. 2001; 56:M644-M649.

Somers JM, Goldner EM, Waraich P, Hsu L. Prevalence and incidence studies of anxiety disorders: A systematic review of the literature. Canadian Journal of Psychiatry. 2006; 51:100-113. [PubMed: 16989109]

Tambs K. Moderate effects of hearing loss on mental health and subjective well-being: Results from the Nord-Trondelag Hearing Loss Study. Psychosomatic Medicine. 2004; 66:776-782. DOI: 10.1097/01.psy.0000133328.03596.fb [PubMed: 15385706]

Taylor WD, Aizenstein HJ, Alexopoulos GS. The vascular depression hypothesis: Mechanisms linking vascular disease with depression. Molecular Psychiatry. 2013; 18:963-974. DOI: 10.1038/Mp. 2013.20 [PubMed: 23439482]

Teng EL, Chui HC. The Modified Mini-Mental State (3MS) examination. Journal of Clinical Psychiatry. 1987; 48:314-318. [PubMed: 3611032]

Valentijn SA, van Boxtel MP, van Hooren SA, Bosma H, Beckers HJ, Ponds RW, Jolles J. Change in sensory functioning predicts change in cognitive functioning: Results from a 6-year follow-up in the Maastricht aging study. Journal of the American Geriatrics Society. 2005; 53:374-380. DOI: 10.1111/j.1532-5415.2005.53152.x [PubMed: 15743277]

Wallhagen MI, Strawbridge WJ, Shema SJ, Kurata J, Kaplan GA. Comparative impact of hearing and vision impairment on subsequent functioning. Journal of the American Geriatrics Society. 2001; 49:1086-1092. [PubMed: 11555071]

World Health Organization. Grades of hearing impairment. Prevention of Blindness and Deafness. 2014. Retrieved from http://www.who.int/pbd/deafness/hearing_impairment_grades/en 


\section{Table 1}

Baseline Characteristics of Analytic Cohort.

\begin{tabular}{|c|c|c|c|c|}
\hline Characteristics & $\begin{array}{r}\begin{array}{r}\text { No hearing } \\
\text { impairment }\end{array} \\
n=731\end{array}$ & $\begin{array}{r}\begin{array}{c}\text { Mild hearing } \\
\text { impairment }\end{array} \\
n=649\end{array}$ & $\begin{array}{r}\text { Moderate or greater } \\
\text { hearing impairment }\end{array}$ & $p$ value \\
\hline Age, $M(S D)$ & $73.2(2.7)$ & $74.0(2.7)$ & $74.7(2.9)$ & $<.001$ \\
\hline \multicolumn{5}{|l|}{ Gender, $n(\%)$} \\
\hline Male & $274(37.5)$ & $312(48.1)$ & $232(65.9)$ & $<.001$ \\
\hline Female & $457(62.5)$ & 337 (51.9) & $120(34.1)$ & \\
\hline \multicolumn{5}{|l|}{ Race, $n(\%)$} \\
\hline White & $425(58.1)$ & $465(71.7)$ & $279(79.3)$ & $<.001$ \\
\hline Black & $306(41.9)$ & $184(28.4)$ & $73(20.7)$ & \\
\hline \multicolumn{5}{|l|}{ Education, $n(\%)$} \\
\hline Less than high school & $114(15.6)$ & $110(17.0)$ & 83 (23.6) & .034 \\
\hline High school graduate & $239(32.7)$ & $212(32.7)$ & $107(30.4)$ & \\
\hline Some college & $378(51.7)$ & $327(50.4)$ & $162(46.0)$ & \\
\hline \multicolumn{5}{|l|}{ Smoking status, $n(\%)$} \\
\hline Never & $374(51.2)$ & $300(46.2)$ & $136(38.6)$ & .001 \\
\hline Former & $305(41.7)$ & $312(48.1)$ & $185(52.6)$ & \\
\hline Current & $52(7.1)$ & $37(5.7)$ & $31(8.8)$ & \\
\hline \multicolumn{5}{|l|}{ Study site, $n(\%)$} \\
\hline Memphis, Tennessee & $310(42.4)$ & $326(50.2)$ & $190(54.0)$ & $<.001$ \\
\hline Pittsburgh, Pennsylvania & $421(57.6)$ & $323(49.8)$ & $162(46.0)$ & \\
\hline Hypertension, $n(\%)$ & $461(63.1)$ & $386(59.5)$ & $211(59.9)$ & .350 \\
\hline Diabetes mellitus, $n(\%)$ & $103(14.1)$ & $104(16.0)$ & $62(17.6)$ & .289 \\
\hline Stroke history, $n(\%)$ & $10(1.4)$ & $12(1.9)$ & $3(0.9)$ & .456 \\
\hline Hearing aid use, $n(\%)$ & $3(0.4)$ & $58(9.0)$ & $166(47.2)$ & $<.001$ \\
\hline Pure-tone average $(\mathrm{dB}), M(S D)$ & $18.1(5.1)$ & $32.3(4.3)$ & $50.5(9.1)$ & $<.001$ \\
\hline Anxiety, $n(\%)$ & $142(19.4)$ & $148(22.8)$ & $84(23.9)$ & .155 \\
\hline Depression (CES-D), $n(\%)$ & $77(10.5)$ & $80(12.4)$ & $41(11.6)$ & .565 \\
\hline
\end{tabular}

Note. Hearing impairment is defined by the speech-frequency pure tone average of thresholds at $0.5,1,2$, and $4 \mathrm{kHz}$ in the better-hearing ear (none $<25 \mathrm{~dB}$ HL, mild impairment 25-40 dB HL, moderate or greater $>40 \mathrm{~dB}$ HL). CES-D = Center for Epidemiologic Studies Depression Scale. 


\section{Table 2}

Odds of Anxiety by Hearing Impairment Category.

\begin{tabular}{lccccc}
\hline & & \multicolumn{2}{c}{$\begin{array}{c}\text { Mild hearing } \\
\text { impairment }\end{array}$} & $\begin{array}{c}\text { Moderate or greater } \\
\text { hearing impairment }\end{array}$ \\
\cline { 5 - 6 } Regression model & ref & $1.33[1.02,1.74]$ & $1.65[1.19,2.29]$ \\
No hearing & impairment & OR (95\% CI) & OR (95\% CI) \\
\hline Base (age, sex) & ref & $1.32[1.01,1.72]$ & $1.60[1.15,2.22]$ \\
Base + Demographic Factors (race, education) & ref & $1.32[1.01,1.73]$ & $1.59[1.14,2.22]$ \\
$\begin{array}{l}\text { Base + Demographic Factors + Cardiovascular Factors (stroke, smoking, diabetes, } \\
\text { hypertension) }\end{array}$ & & & & & \\
\hline
\end{tabular}

Note. Hearing impairment is defined by the speech-frequency pure tone average of thresholds at $0.5,1,2$, and $4 \mathrm{kHz}$ in the better-hearing ear (none $<25 \mathrm{~dB}$ HL, mild impairment $25-40 \mathrm{~dB}$ HL, moderate or greater $>40 \mathrm{~dB} \mathrm{HL}$ ). OR = odds ratio; $\mathrm{CI}=$ confidence interval. 